
Revue
de l'histoire
Revue de l'histoire des religions
des religions
$1 \mid 2012$
Judaïsme / christianisme : syncrétismes, antinomies, dissonances

\title{
De David Reubeni au Juif Errant : dans les pas du "Juif au soulier"
}

From David Reubeni to the Wandering Jew: following the steps of the "Jew with a shoe"

\section{François Delpech}

\section{(2) OpenEdition}

Journals

\section{Édition électronique}

URL : http://journals.openedition.org/rhr/7834

DOI : 10.4000/rhr.7834

ISSN : 2105-2573

Éditeur

Armand Colin

Édition imprimée

Date de publication : 1 mars 2012

Pagination : 53-84

ISSN : 0035-1423

Référence électronique

François Delpech, « De David Reubeni au Juif Errant : dans les pas du " Juif au soulier » », Revue de I'histoire des religions [En ligne], 1 | 2012, mis en ligne le 01 mars 2015, consulté le 19 avril 2019. URL http://journals.openedition.org/rhr/7834; DOI : 10.4000/rhr.7834 


\section{De David Reubeni au Juif Errant : dans les pas du «Juif au soulier»}

Plusieurs documents du XVI siècle attestent que David Reubeni était connu sous le nom de "Juif au soulier». À propos de cette énigmatique appellation on examine les rapports anciens du métier de la chaussure avec la prophétie et le messianisme. Certaines versions ibériques de la légende paneuropéenne du Juif Errant indiquent que l'identification traditionnelle de ce personnage à un cordonnier de Jérusalem qui aurait insulté le Christ semble avoir connu un enracinement précoce et privilégié dans les croyances et le folklore péninsulaires. On peut légitimement supposer que s'est produite en Espagne et au Portugal une interaction entre cette légende médiévale et les rumeurs qui ont dû circuler à propos du vagabond illuminé exécuté en 1538.

\section{From David Reubeni to the Wandering Jew: following the steps of the "Jew with a shoe"}

Several documents of the $16^{\text {th }}$ century vouch that David Reubeni was known as "the Jew with a shoe". About this strange nick-name the author investigates the old relations of the shoemaking craft with prophecy and messianism. Some Iberian versions of the paneuropean legend of the Wandering Jew show that the traditional identification of this figure to a cobbler from Jerusalem who was supposed to have insulted Christ seems to have had some early and special roots in peninsular beliefs and folklore. It can reasonably be supposed that in Spain and Portugal an interaction took place between this medieval legend and some of the rumours which probably spread about the enlightened wanderer executed in 1538. 


\section{UN MYSTÉRIEUX SOULIER}

Des multiples énigmes qui entourent l'atypique personnage de David Reubeni, ce juif vagabond et «prophète» qui hanta les cours royales et les communautés hébraïques de l'Occident chrétien dans les premières décennies $\mathrm{du} \mathrm{XVI}^{\mathrm{e}}$ siècle $^{1}$, la moindre n'est pas celle de l'étrange surnom de «judío del zapato» que lui prêtent certains textes, dont aucun ne précise la signification ni l'origine qu'il convient d'attribuer à semblable appellation.

Cette dernière n'apparaît, semble-t-il, qu'après que tout fut consommé (et consumé): on la voit en effet mentionnée de façon très explicite dans un relevé des sambenitos conservés dans la cathédrale de Badajoz (réalisé au XVII ${ }^{\mathrm{e}}$ siècle par un chanoine pénitencier de cette dernière), où il est indiqué que «David judío que deçian del çapato. Hijo que dixo ser del Rey Salomón y hermano del Rey Juzep, natural del desierto de Hobot» vint au Portugal en 1525 et «dogmatiço y convirtio muchos xrianos a la ley muerta de los judios», pour être finalement «relaxado en persona año de $1538 »^{2}$.

1. Sur la carrière, les pérégrinations et la personnalité de ce prétendu missionnaire juif (peut-être d'origine éthiopienne), venu en Occident solliciter, au nom des «tribus perdues» d'Israël et de son frère (un certain Joseph, roi de quelques-unes de ces tribus), l'aide diplomatique et militaire du Pape et de l'Empereur afin de renforcer l'armée qu'il disait vouloir lancer contre l'empire ottoman, voir l'article que lui consacre l'Encyclopaedia Judaica, t. XIV, Jérusalem, 1971, col. 114-115, le livre de Léa Sestieri, David Reubeni: un ebreo d'Arabia in missione secreta nell' Europa del Cinquecento, Gênes: Marietti, 1991 (qui comporte une traduction du Journal de Reubeni) et Mercedes García-Arenal, "“Un réconfort pour ceux qui sont dans l'attente". Prophétie et millénarisme dans la péninsule Ibérique et au Maghreb ( $\mathrm{xVI}^{\mathrm{e}}-\mathrm{XVII}^{\mathrm{e}}$ siècles)», Revue de l'Histoire des Religions, 220 (4), 2003, p. 445-486 (p. 465-470). Après d'inscrutables et peut-être mythiques visites à Alexandrie, Jérusalem, Safed, Damas, notre pèlerin messianique commence sa carrière diplomatique européenne à Venise en 1523 et l'achève sur un bûcher (à Badajoz?) en 1538, après s'être entretenu, au fil des années, avec le Pape Clément VII et Jean III, roi du Portugal, et avoir éveillé par ses «ambassades» l'attention de Charles Quint. Son influence s'est cependant surtout exercée dans les communautés de «nouveaux chrétiens» au Portugal et en Espagne, où il semble avoir suscité assez d'agitation millénariste pour s'attirer les foudres de la couronne impériale et de l'Inquisition.

2. Voir Antonio Rodríguez Moñino, «Les judaïsants à Badajoz de 1493 à $1599 »$, Revue des Etudes Juives, 115, 1956, p. 73-86 (p. 75 sq., 81) et id., «La 
Cette allusion est confirmée par d'autres textes, notamment par la Carta do primeiro Arcebispo de Goa ao povo de Israel, éditée avec le Tratado que fez mestre Hieronimo, medico do Papa Benedicto XIII contra os judeus (Goa, 1565), où l'on peut lire que «Em nossos dias no tempo del Rey dom João o terceiro de Portugal, destas partes orientaes foy hum ribaldo que em Hespanha chamarão o judeu do çapato, dizendo que vinha donde estavão os tribus de Israel. E soo este appellido foy bastante pera ser tido em Hespanha e dos judeus de Africa como Messias [...] $»^{3}$. Ce texte fournit, on le voit, une précision capitale: le surnom de «juif au soulier»a une relation symbolique avec la fonction messianique attribuée au personnage par ses coreligionnaires. Son sens et la raison de cette relation restent cependant implicites et opaques. Il semble même que l'association en question ne s'est imposée que tardivement: une lettre de l'inquisiteur Selaya à Jean III datée de 1528 mentionne en effet l'activité messianiste de Reubeni sans faire la moindre allusion au surnom cité4.

Un dernier texte donne enfin une indication sur le sens du surnom, mais l'origine tardive du document (copie supposée d'un registre d'autodafés célébrés à Évora en 1542) et ses flagrantes inexactitudes laissent supposer que la dénomination de «Juif au soulier» doit relever, comme le reste de la notice, d'une élaboration légendaire postérieure aux événements et que l'explication qui en est donnée est peut-être de nature purement spéculative ${ }^{5}$. Qu'elle relève ou non d'une rationalisation secondaire, elle s'inscrit néanmoins, comme on le verra, dans le fil d'une tradition attestée par ailleurs et mérite de ce fait d'être retenue: «O Judeu do Çapato, dizem que foy çapateyro, o qual veyo da India Oriental a Portugal, e lhes

muerte de David Reubeni en Badajoz (1538)», Revista de Estudios Extremeños, 15, 1959, p. 389-395.

3. Cité par I.-S. Révah, «David Reubeni exécuté en Espagne en 1538 », Revue des Etudes Juives, 117, 1958, p. 128-135 (p. 132).

4. «[...] el dicho judio venía a dar buenas nuevas a los creyentes y para dezirles que estoviesen apercibidos para yr a recebir al falso mexias que el pedricó, porque un rey, hermano suyo, los avía de llevar a Tierra de Promissión [...]» (cité par I.-S. Révah, op. cit., p. 129).

5. Voir I.-S. Révah, op. cit., p. 132-135, qui indique que la notice en question (ms. 958 des Archives de la Torre do Tombo), connue par une compilation faite à la fin du XVIII ${ }^{\mathrm{e}}$ siècle, est sans doute d'origine espagnole et se distingue par son «caractère inauthentique et purement légendaire». Voir également L. Sestieri, $o p$. cit., p. 47-48. 
meteo na cabeça e persuadio aos moradores do tal Reyno, que era o Messias esperado, e que vinha do Eufrates de se manifestar aos que allí estavão, e todos em Portugal o tiverão por tal, e o crerão $[\ldots] .{ }^{6}$.

Plus explicite que les autres, ce texte fait donc de Reubeni un «çapateyro», ce qui, à première vue, devrait rendre compte de l'étrange surnom «Judeu do çapato», que les autres mentions du personnage laissent inexpliqué

Malheureusement cette explication pose plus de problèmes qu'elle n'en résout. Quoique s'inscrivant dans la perspective d'une démystification annoncée du personnage, clairement dénoncé comme un imposteur, elle est en elle-même fort invraisemblable et semble relever d'une anti-légende aussi fabuleuse que les fausses assertions messianiques qu'elle prétend démasquer. On ne voit pas bien en effet comment ce voyageur-ambassadeur qui fréquentait, d'un pays à l'autre, les cours pontificale, royales et nobiliaires aurait pu exercer la profession de cordonnier: il se présentait comme un chef de guerre de haut lignage, «fils» de Salomon et frère d'un roi des fameuses Tribus Perdues, et il n'y a aucune allusion dans son journal à un lien quelconque avec l'humble métier des «réparateurs de la chaussure humaine». Il y a bien sûr lieu de supposer que ses récits au sujet de ses origines, de sa mission hautement politique et de ses pérégrinations orientales antérieures à son surgissement dans l'Histoire vérifiable (Venise, 1523) sont pour la plupart largement imaginaires et qu'il a très bien pu, dans ses quarante premières années, être amené ici ou là à exercer une profession artisanale, qu'il aurait ensuite manifestement abandonnée pour se livrer à l'aventureuse carrière «missionnaire» qu'on lui connaît.

Il n'est pas interdit non plus de supposer qu'une fois tombé dans les griffes de l'Inquisition il a pu, torturé ou non, avouer les humbles origines supposées plus haut. Une fois l'affaire ébruitée (avant ou après son exécution, qui a certainement fait beaucoup

6. I.-S. Révah, op. cit., p. 134. Remarquer que l'auteur de la notice assure également, comme la lettre de l'archevêque de Goa, que Reubeni n'était en fait pas juif.

7. Voir l'allusion à «Davit judeu estranjeiro que por alcunha se chamava do çapato » citée par M. García-Arenal, op. cit., p. 467, n. 71, qui semble provenir des documents de l'Inquisition d'Évora (1553) relatifs au procès d'Alonso Fernández de Medellín. 
de vagues et suscité de nombreux commentaires, vu l'apparente célébrité du personnage), la nouvelle a pu donner lieu aux rumeurs les plus diverses. Qu'un personnage de si haute volée et exotique prestige ait pu n'être finalement qu'un savetier fabulateur, voilà qui rendait l'imposture plus manifeste, plus captivante à raconter, plus exemplairement admonitoire dans la perspective, alors largement ouverte, des campagnes antisémites visant à la marginalisation des conversos.

On peut encore, pour en finir avec les hypothèses, imaginer que le mot « zapato » et son association au personnage de Reubeni procèdent en l'occurrence d'une déformation (ou parodie) populaire d'un autre mot - par exemple «çabato »- et impliquent une allusion au sabbat, ou au mythique fleuve Sambation, qui marquait, comme on sait, la frontière au-delà de laquelle se trouvait précisément la retraite cachée des Tribus Perdues, dont Reubeni prétendait provenir8. La minceur du corpus documentaire, les incertitudes et lacunes du dossier recommandent cependant de ne pas trop accumuler les hypothèses, lesquelles ne peuvent qu'amener à solliciter à l'excès des textes certes convergents, mais trop incertains et indirects pour qu'on puisse en tirer des conclusions très claires.

\section{DE QUELQUES SAVETIERS PROPHÈTES}

Un éclairage latéral et comparatif nous aidera peut-être à éviter les apories qu'implique un dossier textuel si fragile et permettra au moins, sinon de résoudre l'énigme, du moins de la recadrer dans le contexte du réseau des représentations imaginaires qui en constituent l'arrière-plan et d'en entrevoir les différents registres signifiants.

Remarquons d'abord que de nombreux juifs ibériques s'appellent Zapata et qu'ils sont encore plus nombreux à exercer, traditionnellement, le métier de «zapatero». Il est d'autre part notoire que beaucoup de ces cordonniers judaisants apparaissent sur les tableaux de chasse de l'Inquisition: la copie des sambenitos

8. C'est ce que suggérait Cecil Roth dans un travail ( $«$ Le martyre de David Reubeni » Revue des Etudes Juives, 116, 1957, p. 93-95) dont I.-S. Révah (op. cit., p. 132) a contesté fermement les conclusions. 
de Badajoz mentionnée plus haut, où figure justement le nom de Reubeni, en compte un nombre impressionnant ${ }^{9}$.

Il y a lieu enfin de retenir que l'Occident chrétien a connu, du Moyen Âge au XVII ${ }^{e}$ siècle, une solide et curieuse tradition de «cordonniers-prophètes» (ou transmetteurs de prophéties). Qu'il suffise de rappeler par exemple ce Benvenuto, dit l' «Asdenti», savetier parmesan né dans le premier quart du $\mathrm{XIII}^{\mathrm{e}}$ siècle, que Dante cite à deux reprises (dans le Banquet, IV, 16, 6, et dans la Divine Comédie, Enfer XX, 118-120, où on le voit subir, dans le huitième cercle infernal, le même éternel châtiment que Michel Scot et une série d'autres devins, magiciens et astrologues ${ }^{10}$. Ce «quidam simplex homo, qui habet intellectum illuminatum ad predicendum futura» commentait, quoique illettré, les prophéties bibliques aussi bien que celles de Merlin, de Joachim de Flore et des Sibylles: Salimbene de Adam évoque sa grande notoriété ( $\ll t$ de diversis partibus mundi multi veniunt ad ipsum interrogandum»), son humilité («Et est curialis homo et humilis et familiaris et sine pompa et vanagloria, nec aliquid dicit affirmando, sed dicit: "Ita videtur michi, et ita intelligo ego istam scripturam"»), et le rôle de pacificateur qu'il a joué dans des conflits locaux ${ }^{11}$. Dante ne lui a pas pardonné, semble-t-il, ses prophéties anti-impériales.

Un autre cas notoire est celui de Jakob Böhme, le «cordonnier théosophe » de Görlitz: son œuvre mystique immense fait de lui l'un des piliers de la tradition philosophico-religieuse allemande. Reçu en 1599 dans la corporation de la chaussure, cet artisan illuminé avait connu, avant de se décider à écrire, un cursus initiatique marqué par de mystérieuses découvertes, rencontres et visions: il avait notamment reçu dans la boutique de son patron, lors de ses années d'apprentissage, la visite d'un inconnu, un étranger mal vêtu mais d'allure noble, qui voulait acquérir une paire de souliers; en l'absence du maître artisan, le jeune apprenti avait d'abord refusé de la lui vendre, puis, le voyant insister, lui avait proposé pour le

9. A. Rodríguez Moñino, «Les judaïsants...», p. 77-84: voir les ${ }^{\circ} 55,60$, $63,75,87,88,93,94,97,98,119,125,137,139,142,148,155,157,167,169$, $170,173,174,184,192,193,194,195,196,197,199,200,210,216,229$, sur une liste globale de 231 condamnations (entre 1493 et 1599).

10. Voir Dizionario Biografico degli Italiani, Rome: Ist. della Enciclopedia Italiana, t. VIII, 1966, p. 685-689.

11. Salimbene de Adam, Chronica, t. II (a. 1250-1287), G. Scalia éd., Turnhout: Brepols, 1999, p. 691, 776 sq., 800 sq., 803. 
décourager un prix exorbitant, que l'inconnu paya sans sourciller. Sorti de la boutique ce dernier appela Jakob par son nom, le fit venir à lui et, le fixant du regard en lui serrant la main, lui annonça, avant de s'éclipser sur la route, sa grandeur future, sa transformation en un autre homme qui étonnerait le monde et recevrait la grâce divine $^{12}$. Comme l'a pertinemment souligné Flavio Cuniberto, ce personnage symbolique et surnaturel est à l'évidence l'une des incarnations hiérophaniques de ce type traditionnel de voyageur omniscient, immortel et prophète que la tradition juive identifie à Elie et la gnose musulmane à Khadir, guide spirituel itinérant des obscurs inconsciemment voués à la révélation mystique ${ }^{13}$. Pour Böhme le chemin de l'illumination est donc passé par la boutique,

12. L'épisode est relaté par Abraham von Frankenberg dans sa biographie de Böhme (Historischer Bericht, dont la première version, en latin, est de 1637): voir Alexandre Koyré, La philosophie de Jacob Böhme, réed., New York: Franklin, 1968, p. 17, et les commentaires que fait sur cet épisode Flavio Cuniberto, Jakob Böhme, Brescia: Ed. Morcelliana, 2000, p. 31-34.

13. Ibid., p. 32 sq. Il y aurait lieu de mettre en relief les analogies de cet épisode initiatique avec certaines versions de la légende du Juif Errant (qui se présente à la boutique d'un cordonnier pour lui demander une paire de chaussures neuves ou faire réparer les siennes, ou qui est lui-même un ancien cordonnier qui avait fort mal reçu le Christ lorsque ce dernier avait souhaité faire une pause dans sa boutique lors du Via Crucis): voir par exemple la version catalane recueillie par Joan Amades (Folklore de Catalunya - Rondallística, Barcelone: Selecta, $2^{\mathrm{e}}$ éd., 1982, p. 480 sq., $\mathrm{n}^{\circ} 143$, «El sabateret pobret, pobret») où un cordonnier pauvre offre des chaussures neuves à un mendiant qui s'avère être le Juif Errant, lequel donne à son bienfaiteur, pour le remercier, le noyau d'une pèche qu'il a cueillie au Paradis. Sur le personnage de Khadir, «prophète-bis» de la mystique musulmane (qui apparait souvent dans les chroniques historiographiques hispano-musulmanes et dans le folklore morisque), voir Hassan Elboudrari, «Entre le symbolique et l'historique: Khadir immémorial», Studia Islamica, 76, 1992, p. 25-39; Françoise Aubaille-Sallenave, «Al-Khidr, "L'homme au manteau vert" en pays musulmans : ses fonctions, ses caractères, sa diffusion», Res Orientales, 14, 2002 (Charmes et sortilèges. Magie et magiciens), p. 11-35; François Delpech, «Salomon et le jeune homme à la coupole de verre. Remarques sur un conte sapiential morisque», Revue de l'Histoire des Religions, 223 (4), 2006, p. 439-481. Je reviendrai ailleurs sur les rapports du «caballero del verde gabán» de Cervantes avec cette figure musulmane. Noter enfin que Khadir est considéré comme l' «original» du Juif Errant Ahasverus par Haim Schwarzbaum, Biblical and extra-biblical legends in islamic folk-literature, Walldorf-Hessen: Verlag für Orientkunde, 1982, p. 167$168, n$. 215, ce que pourraient confirmer les légendes compilées à son sujet par René Basset, Mille et un contes, récits et légendes arabes, $2^{\mathrm{e}}$ éd., Paris: J. Corti, 2005, t. II, p. 273-275 ( ${ }^{\circ} 83$, «Les changements du monde»), qui font apparaître que Khadir et le Juif Errant partagent, de par leur immortalité et leurs tournées (avec retours récurrents et cycliques aux mêmes endroits), la fonction de témoins privilégiés des mutations géomorphologiques. 
les arcanes de l'initiation artisanale et du «métier» ouvrant la voie au «mystère » théosophique ${ }^{14}$.

Or il est intéressant de constater que c'est dans la péninsule Ibérique, et plus particulièrement au Portugal, dans un contexte mental et politique marqué à la fois par la culture marrane, le problème des conversos et la montée de ce qui deviendra le millénarisme sébastianiste, que l'on voit fleurir avec le plus d'éclat, au seizième siècle, le type du cordonnier prophète (et même celui du cordonnier-messie).

On connaît notamment le cas illustre de Gonçalo Eanes Bandarra, ce cordonnier de Trancoso, dont les Trovas prophétiques en vers, pénétrées d'idéologie messianique joachimiste, ont joué un rôle décisif dans la diffusion de la mythologie du sébastianisme, à travers l'association du mythème de l' «Encuberto » à la personne du malheureux jeune roi lusitanien disparu corps et biens à la «bataille des trois rois » $\left(\right.$ Ksar el Kebir, 1578) ${ }^{15}$.

Le thème sébastianiste de l'attente d'un «roi caché», dont le retour - annonce de l'accomplissement du «cinquième empire» (motif extrapolé à partir des prophéties bibliques de Daniel) - inaugurera le triomphe final de la vraie Foi et le destin eschatologique de la couronne portugaise, apparaît en partie comme une variante christianisée du millénarisme juif, et plus particulièrement de l' «espérance d'Israël » ${ }^{16}$. Précisément polarisée sur le rôle messianique supposé des légendaires Tribus Perdues, cachées quelque part dans un coin inaccessible de la planète, dont la sortie récente constituait justement la bonne nouvelle apportée par David Reubeni, cette espérance impliquait prioritairement, pour

14. Sur le passage du «métier» (ministerium) au «mystère» (mysterium), voir F. Cuniberto, op. cit., p. 27 sq. Sur les aspects initiatiques et «gnostiques» de l'artisanat traditionnel et de l'art de la chaussure en particulier, voir F. Delpech, «Savetiers prodigieux et cordonniers sacrilèges (éléments pour une mythologie de la praxis artisanale)», in Anthropology of the Indo-European world and material culture (Proceedings of the $5^{\text {th }}$ International Colloquium of Anthropology of the Indo-European world and comparative Mythology), Marco V. García Quintela, Francisco J. González García, Felipe Criado Boado éds., Budapest : Archaeolingua, 2006, p. 307-332.

15. Voir Raymond Cantel, Prophétie et messianisme dans l'œuvre d'Antonio Vieira, Paris: Ed. Hispanoamericanas, 1960, p. 21-39, Lucette Valensi, Fables de la mémoire. La glorieuse bataille des trois rois, Paris: Seuil, 1992 p. 166-168.

16. Voir Yves-Marie Bercé, Le Roi Caché. Sauveurs et imposteurs. Mythes politiques populaires dans l'Europe Moderne, Paris: Fayard, 1990, p. 350 sq. et passim. 
les Marranes et les conversos cryptojudaïsants, la perspective d'une libération du joug chrétien et d'un retour à la Terre Promise, sous la direction d'un leader charismatique inspiré ${ }^{17}$.

C'est encore un cordonnier, Simon Gomes, qui quelques décennies plus tard (vers la fin du XVI ${ }^{\mathrm{e}}$ siècle), apporte sa contribution, toujours au service du sébastianisme, à cette mystique collective lusitanienne de l'attente du souverain sauveur ${ }^{18}$.

Quant à Luiz Dias, savetier et/ou tailleur ${ }^{19}$, répétitivement condamné (en 1538 et 1539) et finalement brûlé par l'Inquisition de Lisbonne, il avait allègrement franchi les limites du ministère prophétique pour devenir lui-même le «Messie de Setúbal», ses prétentions et son destin recoupant indirectement sur plusieurs points l'affaire David Reubeni ${ }^{20}$.

En Espagne cette fois, peu après la guerre des Alpujarras (en 1572), don Pedro de Deza rapporte dans une lettre avoir eu connaissance, au début du conflit, par l'intermédiaire d'un cordonnier, d'un écrit prophétique chrétien: «vino a mí un çapatero vezino nuestro, hombre muy viejo, con un libro antiquísimo scripto de mano [...] En todo el libro no se contenía otras cosas sino profecías y pronósticos extraños, entre los quales avía uno que tractava las cosas del levantamiento deste Reyno [...]». Ici encore il s'agit de l'annonce d'un Messie caché : «[...] vendrá el encubierto a dar salvación a los Christianos y a destruir los Agarenos [...] $»^{21}$.

17. Sur l'emprise du mythe des Tribus Perdues sur la culture de la péninsule Ibérique au «Siècle d'Or» (bien au-delà des seuls milieux hébraïsants), voir Giuliano Gliozzi, Adam et le Nouveau Monde. La naissance de l'anthropologie comme idéologie coloniale: des généalogies bibliques aux théories raciales (1500-1700), trad. fr., Lecques: éd. Théètête, 2000, et M. García Arenal, op. cit., p. 459-465.

18. L. Valensi, op. cit., p. 192.

19. Savetiers et remendones, qui ont en commun la caractéristique (considérée comme ontologiquement juive) de préférer l'ancien au nouveau, échangent volontiers leurs attributs et attributions et sont fréquemment associés ou identifiés dans les représentations ibériques auriséculaires. Il en va de même pour zapateros et sastres, marques du même stigmate racial et professionnel.

20. Voir I.-S. Révah, op. cit., p. 135, João Lúcio de Azevedo, Historia dos cristãos novos portugueses, Lisbonne, 1921, p. 98 et 448, Teófilo Braga, O Pôvo Português nos seus costumes, crenças e tradições, $2^{\mathrm{e}}$ éd., Lisbonne: Publ. Dom Quixote, 1986, t. II, p. 174, et C. Roth, Histoire des Marranes, trad. fr., Paris : éd. Liana Lévi, 1990, p. 117-119, 138 et 314 (n.1).

21. Voir Louis Cardaillac, Morisques et chrétiens: un affrontement polémique (1492 - 1640), Paris: Klincksieck, 1977, p. 52 sq. et 412 sq. 


\section{GNOSES ARTISANALES}

Je me suis efforcé, dans un travail récent, de montrer, à partir d'un corpus de traditions majoritairement ibériques, que cette association privilégiée entre le métier de cordonnier et le ministère prophétique, laquelle est fortement accentuée dans les cas, si nombreux, où les artisans concernés sont d'origine et de confession (secrète) juives, est dans une large mesure pré-programmée par le riche et complexe folklore relatif à cette profession, laquelle implique - selon un très grand nombre de contes et de légendes - des liens spécifiques et très ambivalents de l'artisan de la chaussure avec la sphère du sacré et celle du pouvoir ${ }^{22}$. Dans nombre de traditions folkloriques, le cordonnier, qui est le plus souvent associé à un seuil ou autre espace liminaire, est en relation avec le monde surnaturel et l'au-delà, visà-vis duquel il exerce, d'une manière ou d'une autre, une fonction médiatrice ${ }^{23}$. Ce rôle de passeur polyvalent tient en partie à ce que l'échoppe urbaine du cordonnier est le lieu par lequel transitent toutes sortes d'informations et de rumeurs, tandis que le savetier ambulant, par ses tournées circumrégionales, parfois lointaines, assure le lien entre centres et périphéries, tout en croisant toutes sortes de vagabonds et voyageurs. Transmetteurs de bruits séditieux ou informateurs de police, les artisans de la chaussure sont ceux qui savent et font circuler. Un don divinatoire, voire magique, leur est souvent attribué, d'où le soupçon d'impiété et d'accointances diaboliques ${ }^{24}$, tandis que le fort potentiel transgressif et agonistique que leur prêtent de nombreux récits transpose le rôle de trublion qu'ils ont souvent été amenés à jouer dans des émeutes urbaines et autres mouvements révolutionnaires (comme dans les festivités, rites initiatiques, et querelles corporatives qui émaillent l'histoire de leur compagnonnage $)^{25}$. Situés au niveau le plus infime de l'échelle sociale, mais revendiquant l'ancienneté et la noblesse professionnelle du «gentle $c r a f t{ }^{26}$, cordonniers et savetiers,

22. Voir F. Delpech, op. cit., notamment p. 311-314 («Le cordonnier et le sacré») et 309-311 ( «Le cordonnier et le roi»).

23. Ibid., p. 314-316 («L'au-delà et les fins dernières »).

24. Ibid., p. 319-323 («Un métier mal famé et diabolique»). Je reviendrai ailleurs sur le thème du «cordonnier sacrilège».

25. Ibid., p. 316-319 («La mètis et l'agôn: la fable artisanale»).

26. Les saints et dieux cordonniers sont généralement des nobles déclassés et/ou des avatars de grands dieux des panthéons préchrétiens (voir ibid., p. 311- 
«chevaliers de la courte lance», sont partie prenante de l'inversion carnavalesque et ont, en tant que tels, rapport aux mutations et liturgies calendaires. D'où la dimension eschatologique qu'il leur arrive d'assumer, notamment lorsqu'est mise en relief leur intervention dans les processus de l'usure et du renouvellement ${ }^{27}$.

Cette mythologie artisanale semble avoir eu un enracinement ancien et une diffusion privilégiée dans les cultures de la péninsule Ibérique (où il appert précisément que le «dieu polytechnicien» panceltique Lugus, dont on connaît les affinités avec l'art de la chaussure, entretenait une relation spécifique avec des confréries de cordonniers) ${ }^{28}$.

Ces prédispositions n'ont toutefois ouvert le chemin au folklore évoqué plus haut que sous l'effet catalyseur d'un ensemble de représentations issues du monde juif péninsulaire (mais aussi, bien sûr, d'images et de regards péninsulaires portés sur le judaïsme), ne serait-ce qu'en raison du quasi monopole juif concernant certains secteurs de la profession. Le type traditionnel du «cordonnier sacrilège » et celui du savetier-prophète prenaient évidemment une coloration particulière lorsqu'ils étaient associés, comme c'était très souvent le cas, au peuple du déicide et de l'espérance messianique: la figure du cordonnier juif blasphémateur et l'identification de Judas à un cordonnier ${ }^{29}$ représentent la face obscure et sacrilège de ce binôme, dont l'aspect mystique et illuminé se manifeste au grand jour dans le halo légendaire dont a fini par se nimber le mystérieux personnage de notre «juif au soulier».

Cette curieuse appellation et l'indication, matériellement invraisemblable mais symboliquement pertinente, selon laquelle il

313). Le rôle rituel du pied et de la chaussure dans les cérémonies celtiques d'investiture et d'accès à la souveraineté explique en partie les arrière-plans grandioses que supposent, souvent dans un registre parodique, les «histoires de cordonnier» et leur mythologie corporative: voir ibid., p. 309 sq., F. Delpech, «Le rituel du Pied déchaussé. Monosandalisme basque et inaugurations indoeuropéennes», Ollodagos (Actes de la Soc. Belge d'Etudes Celtiques), 10, 1997, 55-115, M. V. García Quintela, Manuel Santos Estévez, «Petróglifos podomorfos de Galicia e investiduras reales célticas: estudio comparativo», Archivo Español de Arqueología, 73, 2000, p. 5-26, M. Santos Estévez, M. V. García Quintela, «Petróglifos podomorfos del Noroeste Peninsular: nuevas comparaciones e interpretaciones », Revista de Ciencias Históricas, 15, 2000, p. 7-40.

27. F. Delpech, «Savetiers prodigieux et cordonniers sacrilèges», p. 315 sq.

28. Ibid., p. 312 et n. 35 .

29. Ibid., p. 332 sq. 
aurait été «zapatero» me semblent en effet surdéterminées par le profil «énochien» du type prophétique que Reubeni a certainement incarné aux yeux de ses coreligionnaires ibériques. On sait qu'Énoch, qui partage plusieurs de ses caractéristiques et attributs avec son compère Élie, est ce prophète-voyageur, à la fois éternel et cyclique, que Dieu a gratifié d'expériences et de visions eschatologiques, et dont la querencia ultramarine est précisément la même que celle des Tribus Perdues jouissant, au-delà du fleuve Sambation, de l'état d'absconditio bienheureuse auquel seule mettra un terme la grande réunification de la fin des Temps ${ }^{30}$. Or Énoch est aussi et surtout un «héros civilisateur», qui invente et/ou transmet - comme l'Idris des Musulmans, l'Égyptien Thot et Hermès Trismégiste (auxquels on l'a identifié) - un savoir secret lié à l'écriture ${ }^{31}$, ce qui a fait de lui un maitre des techniques fondées sur un apprentissage initiatique. C'est sans doute ce qui explique que, de fil en aiguille, il ait pu figurer dans plusieurs textes et légendes de la tradition hébraïque sous les traits d'un cordonnier ${ }^{32}$.

Cette confluence imaginaire de la gnose artisanale et de la pensée messianique, ce passage des secrets initiatiques du métier aux mystères eschatologiques (sur lesquels il a été suggéré que se développera, sous le signe d'Énoch et d'Élie, le cheminement théosophique du cordonnier visionnaire Jakob Böhme) $)^{33}$, sont probablement déjà au cœur de la nébuleuse idéologique hispanojudéo-lusitanienne qui a accueilli l'étonnante figure de David Reubeni et finalement construit sa légende posthume de «juif au soulier». La typologie du personnage est en effet on ne peut plus

30. Voir Louis Ginzberg, Les légendes des Juifs, trad. fr., Paris : Cerf, t. I, 1997, p. 95-105 et Pierre Grelot, «La légende d'Hénoch dans les Apocryphes et dans la Bible: origine et signification», Recherches de Sciences Religieuses, 46, 1958 p. 5-26. Sur le lien d'Enoch et Élie avec le thème des Tribus Perdues et le rôle de cette association dans les prophéties de Bandarra et dans l'idéologie des conversos cryptojudaïsants, voir M. García Arenal, op. cit., p. 462 (qui se fonde en partie sur John Edwards, «Elijah and the Inquisition: Messianic Prophecy among Conversos in Spain circa 1500», Nottingham Medieval Studies, 28, 1984, p. 79-94).

31. Voir les articles «Idris» et «Hirmis» de l'Encyclopaedia of Islam ( $2^{\mathrm{e}}$ éd.), Leyde: Brill, 1971, t. III, p. 1030 sq. et 463-465, et Pierre Lory, «Hermès/Idris, prophète et sage dans la tradition islamique», in Présence d'Hermès Trismégiste (Cahiers de l'Hermétisme, Paris, 1988), p. 100-109.

32. Sur cette identification voir Gershom Scholem, La kabbale et sa symbolique, trad. fr., Paris: Payot, 1966, p. 151 (qui se réfère à Isaac l'Aveugle et Moïse Cordovero) et l'article «Énoch» de la Jewish Encyclopedia.

33. Voir F. Cuniberto, op. cit., p. 26-36, 44-46. 
énochienne: ce juif illuminé qui se disait «fils de Salomon» ne jouissait-il pas, comme Énoch et Élie, d'une sorte d'immortalité qui lui permettait de traverser le Temps et de se manifester (cycliquement ?) à différents moments de l'Histoire ? N'était-il pas, lui aussi, issu de cet espace secret et paradisiaque où étaient censées résider les Tribus Perdues en attendant l'heure de la réunification? N'apportait-il pas la bonne nouvelle de la sortie militante de ces inclusi et l'implicite prophétie de la reconquête de Jérusalem, étape majeure de l'âge messianique? Ne réincarnait-il pas, par ses incessants voyages, ses tournées d'ambassades de cours royales en métropoles, ses visites fédératrices des juiveries de la diaspora, sa trajectoire solaire d'Orient en Occident, le type énochien du prophète itinérant (dont la chaussure, pertinent emblème, suffirait seule à signaler la vocation marcheuse) ? Quoique historiquement peu vraisemblable, son association à l'art du cordonnier-savetier, qui répare ou renouvelle, fait du neuf avec du vieux et remet continuellement en marche l'instrument privilégié du voyage, se justifie sur le plan symbolique et sapiential et signe sa parenté avec le prophète qui n'a pas connu la mort.

\section{LE MARCHEUR MAUDIT}

Mais, à la différence de celles d'Énoch, les pérégrinations de David Reubeni ont trouvé leur terme tragique à Badajoz et les espoirs messianiques des marranes et conversos se sont encore une fois éparpillés au vent avec les cendres de l'aventurier hâbleur. Une fois tronqué le cours de sa propagande messianique, les signes n'ont pu alors que s'inverser : le discours chrétien a pu s'emparer de l'image et du souvenir du fantastique personnage, désormais imposteur maudit, et, prenant le relais (et le contre-pied) de la légende judaïsante, les a reconfigurés selon ses canons propres. Recyclant certains éléments de cette légende, une image anti-énochienne était alors, semble-t-il, en gestation dans l'Espagne des statuts de pureté de sang: les fables conversas relatives à Reubeni paraissent, détournées de leur sens et réinterprétées, avoir contribué, bien malgré elles, à la mise en place de ce nouveau dispositif mythico-idéologique.

Cette contre-image, faisant pièce au mythe énochien tout en en récupérant plusieurs composantes, n'est autre que celle du Juif 
Errant, dont on verra justement que les variantes ibériques ont été les premières à en faire un cordonnier. On connaît l'origine composite et ancienne de ce cycle à la fois littéraire, folklorique, iconographique, qui a eu une extraordinaire diffusion en Europe jusqu'au XIX ${ }^{\mathrm{e}}$ siècle. Ses contours topiques se sont tardivement fixés (vers le début du XVII ${ }^{\mathrm{e}}$ siècle) après un long et complexe processus médiéval de cristallisation et de contamination de figures diverses, au cours duquel se sont entrecroisés et surimprimés plusieurs profils:

1. le type du témoin éternellement vivant d'une geste sacrale révolue (saint Jean, ou le moine bouddhiste Pindola),

2. celui du pécheur maudit purgeant à travers les âges une transgression sacrilège commise in illo tempore (Caïn, Malchus ou Judas),

3. l'errant cyclique, répétitif spectateur des vicissitudes de l'Histoire et des métamorphoses de la planète (Taliesin et les génies protéens celtiques, ou encore les «changelins» omniscients de la tradition folklorique européenne $)^{34}$,

4. les entités surnaturelles théoxéniques dont les récurrentes visites sur terre viennent incognito mettre à l'épreuve l'hospitalité des humains (nombreuses traditions ibériques sur ce thème) ${ }^{35}$.

Éternel marcheur à qui tout arrêt, tout repos sont interdits, suite à la malédiction divine que lui a valu l'insulte - accompagnée ou non d'une agression physique - lancée par lui à la personne du Christ au moment de la montée au calvaire, ce juif de Jérusalem ne cesse de fatiguer la planète de ses pas, de hanter répétitivement (et cycliquement) les mêmes lieux, fugacement visités, faisant perpétuellement le pont entre l'ici et l'ailleurs, le proche et le lointain, le présent et le passé, le profane et le sacré ${ }^{36}$. Personnage

34. Voir respectivement Claude Sterckx, Les dieux protéens des Celtes et des Indo-Européens, Bruxelles: Soc. Belge d'Études Celtiques, 1994 et Jean-Michel Doulet, Quand les démons enlevaient les enfants. Les changelins: étude d'une figure mythique, Paris: PUPS, 2002.

35. Voir F. Delpech, "Devine qui vient dîner ce soir" ou les douze aux galères : remarques sur un caso notable (Gibraltar, 1592)», in Les Parentés fictives en Espagne (XVI ${ }^{e}-X V I I^{e}$ siècles), A. Redondo éd., Paris : Publ. de la Sorbonne, 1988, p. 167-193 (en particulier p. 182-184).

36. Voir George K. Anderson, The legend of the Wandering Jew, Providence: Brown Univ. Pr., 1965, Alan Dundes, Galit Hasan-Rokem (éds.), The Wandering Jew. Essays in the interpretation of a Christian Legend, Bloomington: Indiana Univ. Pr., 1986, Gaël Milin, Le cordonnier de Jérusalem. La Véritable Histoire du Juif Errant, Pr. Univ. de Rennes, 1997. 
ambivalent, dans la mesure où il est, quoique exclu et maudit, vecteur d'un lien récurrent des croyants avec l'espace et le temps de l'Histoire Sainte, il assume une dimension eschatologique en ce que son châtiment est cheminement vers une éventuelle rédemption que seule rendra possible la Fin des Temps: cette orientation apocalyptique et cyclologique fait de lui, tout au long des récits de ses visites ou apparitions, le grand annonciateur des catastrophes à venir, le témoin, voire le déclencheur, des mutations géophysiques qui affectent le paysage, l'admoniteur perpétuel de la téléologie messianique qui sous-tend l'Histoire humaine.

On sait que, depuis le Siècle d'Or, la légende de l'éternel marcheur maudit a pris pied en Espagne et au Portugal et qu'elle y a laissé maintes traces dans la littérature et les traditions orales ${ }^{37}$. On sait également que plusieurs imposteurs ont revêtu en Espagne les oripeaux de ce personnage afin de profiter de la crédulité du public et que, peu d'années après la mort de David Reubeni, l'Inquisition n'a pas manqué de mettre la main sur certains d'entre eux ${ }^{38}$.

Le destin de Reubeni a-t-il contribué, à travers les légendes qu'il a manifestement inspirées, à ancrer dans les mentalités et représentations péninsulaires ce type pénitentiel qui n'en était encore qu'à l'état pâteux mais allait vite se préciser et s'imposer comme une des figures majeures de l'imaginaire collectif? Mais, inversement (et

37. Voir Joseph E. Gillet, «Traces of the Wandering Jew in Spain», Romanic Review, 22, 1931, p. 16-27, Oliver Brachfeld, «Note sur "The traces of the Wandering Jew in Spain”», Ibid., p. 317-320, Enrique Martínez López, «La leyenda del Judío Errante en la literatura de cordel española», Bulletin Hispanique, 92 (2) 1990, p. 789-821, Carolina Michaelis de Vasconcellos, «O Judeu Errante em Portugal», Revista Lusitana, 1, 1887-1889, p. 34-45, 2, 1893-1895, p. 74-76.

38. Voir Marcel Bataillon, Varia lección de clásicos españoles, Madrid: Gredos, 1964, p. 81-132 («Peregrinaciones españolas del Judío Errante»), Julio Caro Baroja, Vidas mágicas e Inquisición, Madrid: Taurus, 1967, t. I, p. 353365 («El falso Judío Errante como personalidad mágica»), Augustin Redondo, «Devoción tradicional y devoción erasmista en la España de Carlos V. De la Verdadera información de la Tierra Santa de Fray Antonio de Aranda al Viaje de Turquía», in Homenaje a Eugenio Asensio, Madrid: Gredos, 1988, p. 391-416 (p. 407-410), id., «Folklore, referencias histórico-sociales y trayectoria narrativa en la prosa castellana del Renacimiento. De Pedro de Urdemalas al Viaje de Turquía y al Lazarillo de Tormes », in Actas del IX Congreso de la Asociación Internacional de Hispanistas (Berlin 1986), Frankfort: Vervuert, 1989, t. I, p. 65-88 (p. 74-77 et p. 83 sq., nn. 13 et 14). Voir également María Tausiet, Ponzoña en los ojos. Brujería y superstición en Aragón en el siglo XVI, Saragosse: Inst. «Fernando el Católico», 2000, p. 179-184, et F. Delpech, «"Devine qui vient dîner ce soir”...», p. 176-179. 
complémentairement), le personnage n'a-t-il pas, sous l'influence de ces représentations latentes, progressivement perdu le costume et les attributs de l'ambassadeur inspiré pour mettre ses pieds dans les pas de l'errant maudit? Ce n'est peut-être que rétrospectivement que l'imposteur, désormais démasqué, est apparu comme une première et implicite ébauche des pseudo - «Juifs Errants» qui allaient hanter les chemins des deux Castilles, mais c'est semble-t-il dans cette seule hypothèse que fait sens à nos yeux l'étrange surnom qui lui a été accolé: ce soulier ne serait autre que le pivot sur lequel s'est agencé le passage de la mystique figure énochienne (le savetier prodigieux) à celle du marcheur maudit (le cordonnier sacrilège) et des imposteurs qui lui ont emboîté le pas... Ne pouvant plus avant sans forcer la note nourrir cette hypothèse, on en cherchera quelques confirmations latérales par l'examen de certaines traditions ibériques attestant l'implantation péninsulaire privilégiée et la précoce genèse ibérique du motif du cordonnier maudit et de son corollaire, la définition du Juif Errant comme zapatero sacrilège.

\section{LE SAVETIER SACRILÈGE : VERSIONS IBÉRIQUES}

On trouve en effet, dans la tradition orale de la moitié nord de l'Espagne, un ensemble de légendes topographiques faisant allusion, jusqu'à une époque relativement récente, à propos de telle ou telle lagune galicienne (ou léonaise), au fond de laquelle est censée se trouver une ville engloutie, aux raisons et conditions de cet engloutissement. Ces récits s'apparentent par certains de leurs traits aux légendes européennes relatives aux «visites» du Juif Errant $^{39}$, mais ils relèvent prioritairement d'un cycle narratif plus vaste dont le thème principal est l'étiologie de la catastrophe qui a affecté la localité concernée.

Selon un schéma bien connu, diffusé dans plusieurs cultures indo-européennes, c'est le manque de générosité, voire l'agressivité manifestés par certains habitants de l'endroit à l'égard de visiteurs

39. Cf. supra n. 36. Voir également Jean-Claude Schmitt, Le corps, les rites, les rêves, le temps. Essais d'anthropologie médiévale, Paris: Gallimard, 2001, p. 397-415 («De l'attente à l'errance. Genèse médiévale de la légende du Juif Errant») et l'important article «Ewiger Jude» de l'Enzyklopädie des Märchens, K. Ranke éd., Berlin - New York, 1986, t. IV, col. 577-588. 
étrangers (qui sont en fait des personnages divins voyageant incognito et demandant l'hospitalité), qui amène ces derniers à lancer la malédiction qui va déterminer l'engloutissement de l'agglomération ${ }^{40}$. Ces récits de théoxénies sont restés longtemps très vivants dans les traditions orales ibériques, la péninsule étant censée avoir été de tous temps sillonnée par des apôtres ou par les membres de la Sainte Famille (des imposteurs ont, comme on l'a $\mathrm{vu}$, fréquemment mis à profit ces croyances $)^{41}$.

Dans plusieurs versions galiciennes c'est précisément un cordonnier qui non seulement répond négativement au test de charité hospitalière mais va jusqu'à frapper de son alêne ou de sa forme la mendiante ou le pèlerin qui se sont arrêtés devant sa boutique, sans se rendre compte qu'il s'agit de la Vierge ou du Christ. La ville ou la localité où l'agression a été perpétrée est presque aussitôt engloutie par les eaux : il n'en reste plus qu'une lagune au fond de laquelle on distingue parfois des bâtiments, le sommet d'un clocher ou une girouette, et dont les rives retentissent de temps en temps de mugissements sinistres, attribués à l'âme du cordonnier sacrilège ${ }^{42}$. Des traditions de ce genre sont rapportées à propos de la lagune galicienne de Guá (dite de Santa Cristina) - déjà mentionnée au XVI ${ }^{\mathrm{e}}$ siècle pour ses phénomènes surnaturels par le «licenciado Molina», et considérée localement comme étant le site de l'ancienne «ciudad de Lucerna $y$ villa de Villaverde» des légendes épiques carolingiennes ${ }^{43}$ - et au sujet de la «ciudad asolagada» de Boedo de Lagostille ${ }^{44}$.

40. Voir Dominique Briquel, «Sur une explication antique du nom des Ombriens: une version italique du Déluge» in Mélanges Michel Lejeune, Paris, 1978, p. 45-63 pour le dossier indo-européen, et A. Dundes (éd.), The Flood Myth, Berkeley - Los Angeles - Londres : University of California Pr., 1988.

41. Voir supra n. 38.

42. Voir Luis Monteagudo, «Palafitos. Problemas y leyendas», Revista de Dialectología y Tradiciones Populares, 13, 1957, p. 98-125 (p. 99, 112, 114 sq.) et Ramón Menéndez Pidal, La leyenda de los Infantes de Lara, $3^{\text {e }}$ éd., Madrid: Espasa Calpe, 1971, p. 190 sq.

43. Voir, à propos de la version du «Pseudo-Turpin» et des gestes épiques romanes, Joseph Bédier, Les légendes épiques, t. III, Paris, 1912, p. 152-166 («La ville légendaire de Luiserne ») et Samuel G. Armistead, Joseph H. Silverman, Folkliterature of the Sephardic Jews III. Judeo-spanish ballads from oral tradition (2), Berkeley - los Angeles : UCAL Pr., 1994, p. 247-249. Pour les versions folkloriques modernes voir Luis Cortés y Vázquez, «La leyenda del lago de Sanabria», Revista de Dialectología y Tradiciones Populares, 4, 1948, p. 94-114 et id., «De nuevo en torno a la ciudad sumergida de Lucerna», in Mélanges A. Galmés de Fuentes, t. III, Madrid, 1987, p. 377-387.

44. L. Monteagudo, op. cit., p. 114 sq. 
Ces histoires galiciennes de cordonniers violents et (inconsciemment) sacrilèges sont manifestement à mettre en parallèle avec le «mythe» pyrénéen du «Sabater», où il n'est cependant plus question de villages engloutis. On raconte en effet dans l'arrière-pays catalan («Alto-Ripollés») que tous les sept ans - selon la version recueillie à Gombrén -, ou tous les cent ans version de Ripoll -, la région est visitée par un cordonnier juif qui avait refusé au Christ de le laisser se reposer dans son atelier lors de son ascension au Calvaire et l'avait insulté, ce dont Jésus l'avait puni en le condamnant à une éternelle errance ${ }^{45}$. Il est spécifié dans la seconde de ces versions que souvent l'éternel voyageur ne reconnaît pas les lieux qu'il a visités un siècle auparavant. À San Juan de las Abadesas le nom de «Sabater» est inconnu: l'errant est un juif qui, quoique malade, s'est levé pour insulter le Christ sur son passage, a refusé de lui donner à boire et ne l'a pas laissé se reposer contre le mur de sa maison. Même schéma donc que dans la plupart des relations européennes des visites du Juif Errant. Ces récits sans catastrophe naturelle ne se rattachent donc aux légendes galiciennes que par le motif (autrement placé) du cordonnier inhospitalier.

On remarque cependant que le châtiment condamnant à l'errance est redoublé, à San Juan, de celui d'une éternelle soif et d'une impossibilité de se reposer: fontaines et rivières s'assèchent sur le passage du marcheur maudit et tout arbre ou mur cède à son poids. Ces détails n'apparaissent que rarement et fugitivement dans le cycle européen ${ }^{46}$. Celui de l'éternelle soif reconduit par contre, quoique indirectement, à un motif caractéristique de certaines légendes notamment germaniques - de villes inondées, dans lesquelles la divinité (déguisée) de passage qui demande l'hospitalité dit avoir

45. Josep Romeu i Figueras, «Mitos tradicionales Pirenaicos (Alto Ripollés y Valle de Ribas de Freser) », Pirineos VI (n $\left.{ }^{\circ} 15-16\right), 1950$, p. 137-183, en particulier p. 147-149 («El Sabater»). Ce travail a été réédité (en catalan) dans id., Materials $i$ estudis de folklore, Barcelone: Alta Fulla, 1993, p. 93-125 (voir p. 99-101).

46. Sur la soif du Juif Errant, motif fréquent dans les versions britanniques, voir G.K. Anderson, «Popular survivals of the Wandering Jew in England», in A. Dundes - G. Hasan Rokem (éds.), op. cit., p. 76-104 (p. 78 sqq.), Maria Cristina Sirchia, «L'Ebreo Errante nelle Isole Britanniche: una presenza polimorfica», in L'Ebreo Errante. Metamorfosi di un mito, E. Fintz Menascé (éd.) Milan: éd. Cisalpino (Quadermi di Acme 21), 1993, p. 111-182 (p. 112 sq.), Katharine R. Briggs, A Dictionary of British folktales in the English Language, part B, Folk Legends, t. 2, Londres - New York: Routledge, $2^{\mathrm{e}}$ éd., 1991, p. 595-597. 
grand soif et punit par une inondation la sécheresse à laquelle la condamne le mauvais accueil que lui font les gens du pays ${ }^{47}$. L'occurrence de ce motif dans les versions pyrénéennes du mythe du «Sabater» peut donc apparaître - bien que le thème de l'inondation en soit absent - comme un autre indice de sa solidarité avec les versions galiciennes mentionnées plus haut.

Un autre motif intéressant intervient dans les versions recueillies à San Juan de las Abadesas : une identité entre le marcheur maudit et «l'home de la lluna»y est parfois affirmée ${ }^{48}$. Bien qu'elle apparaisse dans quelques versions du cycle du Juif Errant ${ }^{49}$, cette contamination entre les deux pécheurs maudits est relativement rare: le fait qu'elle apparaisse dans le mythe du «Sabater» est peut-être à mettre en relation avec la dévotion particulière des cordonniers pour le lundi, et sa coïncidence avec le motif de la soif (que le motif lunaire croise dans la mesure où la lune, «mangeuse de nuages » et productrice de marées et inondations, est traditionnellement en relation étroite avec les cycles de l'humidité) $)^{50}$ semble indiquer que certaines formes du mythe du Juif Errant, notamment celles qui se sont imposées dans le folklore de la péninsule Ibérique, recoupent un très ancien complexe de représentations imaginaires et peutêtre de fables concernant l'équilibre du sec et de l'humide ${ }^{51}$. Les légendes galiciennes associant cordonniers et villes submergées confortent évidemment cette hypothèse.

47. Voir Warren R. Maurer, «German sunken city legends», Fabula, 17, 1976, p. 189-214 (p. 194).

48. J. Romeu Figueras, op. cit., p. 148.

49. G.K. Anderson, The legend of the Wandering Jew, p. 103, p. 114 (cf.p. 74), G. Milin, op. cit., p. 119, 122 sq.

50. Voir Pierre Saintyves, L'astrologie populaire et l'influence de la lune, Paris, 1937, p. 80-99 (rapports entre l'eau et la lune).

51. Sur les rapports entre le Juif Errant ( «João d'espera em Deos») et l'arc-en-ciel ( Arco da Velha») dans la tradition portugaise, voir M. Bataillon, op. cit., p. 93 (n. 18). Les rapports entre l'homme dans la lune et l'arc-en-ciel sont connus par ailleurs, ainsi que les rôles respectifs de l'arc-en-ciel et de la lune dans la circulation des eaux entre la terre et le ciel: voir P. Saintyves, op. cit., p. 296-315, Sabine Baring Gould, Curious myths of the Middle Ages, $2^{\mathrm{e}}$ éd., Londres, 1901, p. 190-208 («The man in the moon»), Pilar García Mouton, «El arco iris : geografía lingüística y creencias populares», Revista de Dialectología y Tradiciones Populares, 39 1984, p. 169-190, Gian Luigi Beccaria, I nomi del mondo. Santi, demoni, folletti e le parole perdute, Turin: Einaudi, 1995, p. 68-77, Ira R. Buchler - Kenneth Maddock (éds.), The Rainbow Serpent. A chromatic piece, La Haye, Paris : Mouton, 1978. Voir également Paul Sébillot, Le folklore de France, t. I, $2^{\mathrm{e}}$ éd., Paris: Maisonneuve et Larose, 1968, p. 11-25 et 66-71. 
Le trait le plus original du mythe du «Sabater» reste cependant (du moins dans la version de San Juan de las Abadesas) son inscription intégrale dans la topographie locale. Les traditions européennes relatives au Juif Errant dissocient toutes clairement les deux pôles géographiques et chronologiques de la légende: l'épisode initial péché et malédiction - a eu lieu jadis à Jérusalem à l'époque de la Passion du Christ, mais ce qui est en fait raconté, au devant de cette lointaine toile de fond, c'est une visite plus ou moins récente du marcheur maudit dans un lieu appartenant à la sphère, généralement européenne et «moderne», du hic et nunc. À San Juan en revanche, s'il est bien dit que c'est au moment où le Christ montait au «Calvari» que se situe sa rencontre avec le «Sabater», il est spécifié que ce lieu n'est autre que la montagne qui domine l'esplanade dite «Les Très Creus », où se rendent les fidèles de San Juan de las Abadesas tous les Vendredis Saints lorsqu'ils célèbrent le Via Crucis. Autrement dit le temps et le lieu du mythe sont fantastiquement repliés sur ceux du rite qui le célèbre: le cordonnier sacrilège était bien un habitant de San Juan de las Abadesas, et tout se passe comme si c'était bien dans cette bourgade pyrénéenne (et non à Jérusalem) qu'avait eu lieu la Passion de Jésus... ! Identification mystique hiérophanique, par le biais de la sacralisation spatiale opérée par le rituel, entre le lieu désigné par le récit et celui où se pratique sa réactualisation liturgique, ou simple contamination entre le mythe évangélique et le cycle folklorique, hérité des anciennes théoxénies, des «visites» rendues au territoire péninsulaire par Jésus, la Sainte Famille et quelques saints? Toujours est-il que ce télescopage des plans de «réalité» mis en œuvre par la fiction rapproche singulièrement le «sabater» pyrénéen des cordonniers galiciens: dans les deux cas le sacrilège a été commis «chez nous» et l'espace où nous vivons en porte la marque.

Les traditions galiciennes et celles qui ont été recueillies dans les Pyrénées catalanes sont donc symétriques et complémentaires: dans le premier cas le cordonnier joue le rôle de celui qui reçoit mal (au point de le frapper) le visiteur surnaturel et déclenche par cela même une catastrophe locale; dans le second le cordonnier joue au contraire le rôle du visiteur venu de l'extérieur (personnage à vrai dire mi-réel, mi-surnaturel) qui subit (pour son propre compte exclusivement) les conséquences catastrophiques de la transgression qu'il a commise jadis en recevant mal - et même en frappant - le 
personnage surnaturel qu'est par excellence le Christ. Dans un cas comme dans l'autre cependant, la faute est de même nature et elle est commise par un cordonnier.

Il est clair que, directement et explicitement dans le cas pyrénéen, indirectement et certainement à l'insu des transmetteurs locaux de la tradition dans le cas des légendes galiciennes, ces deux types de légendes sont des adaptations et/ou transformations locales du mythe du Juif Errant.

\section{Le Juif ERrant CORdonNiER : Le CYCLE EUROpÉEN}

On sait en effet que, depuis la publication en 1602 du livret populaire allemand Courte description et histoire d'un juif nommé Ahasvérus (opuscule plusieurs fois réédité, largement diffusé, traduit et encore plus souvent imité, qui a fixé d'une manière quasi définitive et «canonique» la figure de l'éternel marcheur maudit que les nombreuses versions médiévales de la légende présentaient sous un jour multiforme et fluctuant $)^{52}$, s'est répandue dans presque toute l'Europe occidentale - plus particulièrement en Scandinavie, en Allemagne du Sud et dans les pays alpins - une version-type selon laquelle le Juif Errant était cordonnier à Jérusalem lorsqu'il fut maudit par Jésus pour avoir refusé en l'insultant de lui laisser faire une halte en s'appuyant au mur de son échoppe lors de sa montée au Calvaire ${ }^{53}$.

Comme presque partout ailleurs, cette version (d'origine germanique) de la légende a été diffusée dans la péninsule Ibérique, tant sous forme orale qu'écrite ${ }^{54}$. Les versions ibériques peuvent

52. Voir supra nn. 36 et 39, et Aaron Schaffer, «The Ahasver Volksbuch of 1602 », in A. Dundes, G. Hasan Rokem (éds.), op. cit., p. 27-35.

53. Voir notamment les versions alpines, finnoises, suédoises etc. respectivement étudiées par Louis Jaccod, Galit Hasan-Rokem, Bengt af Klintberg (dont les articles sont compilés dans A. Dundes - G. Hasan Rokem (éds.), op. cit.), et G.K. Anderson, The legend of the Wandering Jew, p. 75-105. Toutes ces versions folkloriques sont, de près ou de loin, dépendantes du Volksbuch de 1602 et de ses multiples adaptations (voir ibid., p. 38-70).

54. Voir E. Martínez López, op. cit. et J.E. Gillet, op. cit. Voir également Julio Camarena, Maxime Chevalier, Catálogo tipológico del cuento folklórico español, t. III, Cuentos Religiosos, Alcalá: Centro de Estudios Cervantinos, 2003, p. 202-204 (Cuento tipo 777, «El Judío Errante»), où sont recensées la plupart des versions espagnoles. 
donc, dans une large mesure, être considérées, du moins pour plusieurs d'entre elles, comme de simples extensions péninsulaires du cycle paneuropéen, leurs particularités occasionnelles n'apparaissant dès lors que comme des variations locales sur le schéma canonique.

Dans cette perspective on peut par conséquent légitimement mettre en relation le dossier des cordonniers galiciens responsables de l'engloutissement d'une cité avec les autres versions européennes (notamment suisses, autrichiennes, françaises etc.), où les passages du juif errant sont associés à des changements dans un paysage donné - apparition ou disparition de forêts, de villes, d'espaces cultivés, d'essences végétales etc. ${ }^{55}$, , voire à une catastrophe naturelle du genre raz-de-marée ${ }^{56}$, événements géographiques que l'éternel marcheur, qui revient plus ou moins régulièrement aux mêmes endroits, se contente de constater d'un passage à l'autre, mais dont il est parfois suggéré ou dit qu'il en est le responsable ${ }^{57}$.

La parenté avec les autres versions européennes est, bien sûr, encore plus claire dans les versions catalanes pyrénéennes où, contrairement aux versions galiciennes, le protagoniste du récit est explicitement identifié comme étant le Juif Errant.

La spécificité du cycle galicien tient, on l'a vu, à ce que le thème du savetier sacrilège y a été contaminé avec un type de légende, répandu dans la région ${ }^{58}$, où le visiteur qui maudit le lieu où il a été mal accueilli n'a rien d'un errant lui-même sujet à une malédiction mais est bel et bien un personnage sacré, la seule transgression impliquée dans le récit étant imputable au résident sédentaire qui agresse ce visiteur divin ou lui refuse l'hospitalité. Autrement dit, le scénario développé par les versions galiciennes ne retient de la légende du Juif Errant que son épisode initial (à vrai dire déterminant), antérieur au commencement de l'errance punitive, à savoir le moment de l'offense faite au Christ et de l'immédiate malédiction, et il le transfère à l'époque contemporaine, alors que les

55. G.K. Anderson, The legend..., p. 82 sq., 84 sq.

56. G. Milin, op. cit., p. 129 sq.

57. G.K. Anderson, The legend..., p. 82 ( $\left.\mathrm{n}^{\circ} 46\right), 83\left(\mathrm{n}^{\circ} 49\right.$ et 52$)$, p. $86\left(\mathrm{n}^{\circ} 70\right.$ et 71), p. $90\left(\mathrm{n}^{\circ} 89\right)$ : dans plusieurs de ces cas ce sont les larmes versées par l'errant maudit qui ont engendré la formation d'un lac ( $\mathrm{n}^{\circ} 49,52$ et 89$) \ldots$...

58. Voir supra n.n. 42 et 43 . Voir également Xesus Taboada, Ritos y creencias gallegas, La Corogne: éd. Salvora, 1980, p. 221-235 («Las leyendas de la laguna Antela»). 
récits européens sont pour la plupart des relations d'une apparition du juif errant, longtemps après la perpétration de son péché (qui remonte à l'époque du Christ), lors de l'un de ses passages par telle ou telle localité. Cette inversion de perspective fait que les légendes galiciennes évacuent les thèmes de la malédiction individuelle et de l'errance (la malédiction divine n'a plus d'autre effet que la détermination d'une catastrophe naturelle) et vont jusqu'à oblitérer toute référence au type du Juif Errant, dont il ne reste plus que la figure d'un anonyme cordonnier sacrilège mais désormais sédentaire...

L'enracinement de ces versions dérivées dans une forme quelconque du cycle de l'éternel marcheur (peut-être antérieure à celle qu'a fixée la relation allemande de 1602) est toutefois attesté par le motif du coup porté au visiteur sacré avec une forme de cordonnier ou une alène, détail dont on verra qu'il figure dans certaines versions espagnoles anciennes de la légende du Juif Errant et dont on sait qu'il remonte, à travers les textes médiévaux où ce dernier porte le nom de Buttadeus (qui fait allusion à de semblables coups) ${ }^{59}$, à l'une des étapes les plus antiques de la formation du cycle, à savoir celle qui repose sur la confusion entre deux personnages mentionnés dans les Évangiles, le garde hébreu Malchus et le serviteur du Grand Prêtre (ou le portier du prétoire de Ponce Pilate), lequel donne précisément un coup au Christ au moment où il franchit le seuil du lieu où il vient d'être interrogét ${ }^{60}$.

La dépendance des traditions ibériques que je viens d'examiner vis-à-vis du cycle légendaire du Juif Errant, quoiqu' elle soit inégale selon les deux cas envisagés (puisque dans l'un elle est entière et explicite, dans l'autre partielle et souterraine), doit donc être considérée comme acquise.

Mais cela ne signifie pas nécessairement que ces traditions sont, comme c'est le cas pour la plupart des versions européennes modernes du cycle en question, dérivées de près ou de loin du livret allemand de 1602 qui a, comme on l'a vu, imposé le type d'un Juif Errant cordonnier.

59. G. Milin, op. cit., p. 37-48.

60. Ibid., p. 13-15 et 15-18. Le garde du Grand Prêtre est mentionné dans l'Évangile de Jean (XVIII, 20-22). Le portier du prétoire de Ponce Pilate est connu au Moyen Âge sous le nom de Cartaphile (alias Joseph): ibid., p. 18-23 et 27-39. 


\section{PÉrégrinations ibériQues du CORdONNIER de JÉruSALEM}

Un fait très remarquable doit en effet être pris ici en considération : en Espagne (et nulle part ailleurs) l'attribution au Juif Errant du métier de cordonnier est antérieure (de plus d'un demi-siècle) à la publication du livret allemand.

On la trouve en effet dans un dialogue humaniste anonyme composé en espagnol vers le milieu du XVI ${ }^{\mathrm{e}}$ siècle, le Crotalón ${ }^{61}$ : on sait que ce texte est imité du Songe de Lucien, et qu'il est doublement placé sous le signe de la cordonnerie puisque, conformément au modèle antique, l'un de ses deux protagonistes n'est autre que le savetier Micyle, tandis que l'autre, qui est un coq, est une des réincarnations de Pythagore et avoue avoir été, lors d'une de ses précédentes métamorphoses, l'un de ces charlatans vagabonds qui se font passer pour «Juan de Vota Dios» (c'est l'un des avatars onomastiques ibériques de Johannes Buttadeus), c'est-à-dire ce cordonnier qui habitait à Jérusalem à l'époque du Christ dans la rue de l'Amertume «y que al tiempo que passavan a Cristo preso por aquella calle salió dando golpes con una horma sobre el tablero diciendo, vaya, vaya el hijo de María, y que Cristo le avia respondido: yo iré y tu quedaras para siempre jamas para dar testimonio de mi [...] y deziales yo que en viendome viejo me yva a vañar al rio Xordan y luego bolvia de edad de treynta $y$ tres años que era la edad en que Cristo murio $\gg^{62}$.

Ce témoignage littéraire, qui fait allusion à une croyance latente diffuse dans la société espagnole de la Renaissance, en partie reprise,

61. Ibid., p. 49-52. Voir Cristóbal de Villalón, El Crotalón, éd. A. Rallo, Madrid: Cátedra, 1982, p. 142-148.

62. Ibid., p. 145. La même identification du Juif Errant à un cordonnier apparaît dans la tradition recueillie par Gonzalo Correas dans son Vocabulario de refranes y frases proverbiales (éd. L. Combet, Bordeaux: Bibl. de l'École des Hautes Études Hispaniques, 1967), p. 674 b. : «Tiene el vulgo una hablilla de uno que llaman Juan de Espera en Dios, y dicen los muchachos que era un zapatero que, oyendo el ruido cuando llevaban a crucificar a Nuestro Señor, salió a la puerta con horma y boj en la mano, y dijo: "Allá irás», dando un golpe; y que nuestro Señor respondió: "Yo iré, y tú quedarás para siempre jamás», y que ansí quedó immortal, y se remocece y se aparece de repente entre la gente y se desaparece, como invisible, cuando él quiere, y que le dio gracia que siempre que echasse mano a la bolsa hallase cinco blancas». Les analogies de cette version avec celle du Crotalón, l'onomastique du personnage et le détail, très fréquent dans les versions espagnoles, des «cinco blancas» révèlent que l'on a ici affaire à une tradition spécifiquement ibérique, indépendante de celle qui est issue du livret allemand de 1602, et manifestement antérieure à elle. 
en partie construite et répandue par des imposteurs qui se faisaient passer pour le Juif Errant et soutiraient ainsi de l'argent à leurs naïves victimes, est confirmé par plusieurs procès inquisitoriaux de l'époque dont le plus remarquable concerne, en 1546-1547, un pseudo «Juan de Espera en Dios» qui, dans la région de Tolède, affirmait précisément être ce cordonnier de Jérusalem maudit par le Christ pour l'avoir insulté et menacé de sa forme alors qu'il passait devant son échoppe au moment de la montée au Calvaire ${ }^{63}$.

Même si les versions espagnoles ultérieures de la légende du Juif Errant comme cordonnier ont pu être influencées par le livret allemand, cette tradition a donc manifestement une implantation ibérique spécifique plus ancienne, dont le texte allemand est peutêtre lui-même tributaire, les migrations des juifs espagnols expulsés et de leurs descendants et les réactions locales suscitées par

63. M. Bataillon, op. cit. Voir supra n. 38. Le procès de cet escroc, nommé Antonio Ruiz, révèle un modus operandi analogue à celui qui est décrit dans le Crotalón. On remarque seulement que l'auto-identification du pseudo «Juan de Espera en Dios» à un cordonnier y est moins claire et plus hésitante: selon l'une des dépositions il aurait seulement dit qu'il se trouvait dans la boutique d'un cordonnier au moment du passage du Christ («...respondió que hera Juan despera en Dios y que al tiempo que llevaban a crucificar a Jesu Cristo él estaba en la calle de amargura en una tienda de un çapatero y que salió con una horma dándose golpes en la mano [...] y que luego mostró a esta confesante una horma señalada en la una mano...», cité par M. Bataillon, p. 115, n. 48) alors qu'un autre témoignage semble indiquer qu'il se faisait plutôt passer pour un apprenti travaillant dans la boutique d'un maître (cf. la tradition sur Jakob Böhme): «... él hera mancebo de hedad de hasta veynte años y que estava cosiendo en una tienda de un çapatero y que salió a la puerta con una horma en la mano...» (ibid., p. 116, n. 50). Antonio Ruiz craignait-il qu'on lui demandât, accessoirement, de réparer quelque vieille paire de souliers... ? Toujours est-il que les allégations d'Antonio Ruiz et le récit du Crotalón sont les premières occurrences du motif du Juif Errant comme cordonnier. Remarquer cependant la curieuse allusion - dans la version italienne d'Antonio di Francesco di Andrea (vers 1415), qui évoque un précurseur des charlatans espagnols (voir Salomone Morpurgo, L'Ebreo Errante in Italia, Florence, 1891, p. 20) - au «monosandalisme» du prétendu «Giovanni Votaddio»: «e nonn aveva se none una scharpetta». Ce détail fait étrangement écho au surnom de «Juif au soulier» (comme s'il n'en avait qu'un!) de David Reubeni, lequel pourrait aussi s'expliquer par l'exhibition d'une marque corporelle figurant une chaussure, analogue donc à l'empreinte d'une horma de cordonnier que nos prétendus Juifs Errants portaient gravée sur leurs bras pour attester leur identité. Sur les aspects symboliques et mythiques du monosandalisme dans des contextes ibériques voir F. Delpech «Camino del infierno tanto anda el cojo como el viento. Monosandalisme et magie d'amour», in Enfers et damnations dans le monde hispanique et hispano-américain, A. Molinié-Bertrand, J.P. Duviols (éds.), Paris : Presses Universitaires de France, 1996, p. 175-191, et id., «Le rituel du Pied déchaussé...» (voir supra n. 26). 
celles-ci étant probablement pour quelque chose dans la divulgation européenne de cette forme ibérique de la légende ${ }^{64}$.

Mais qu'en est-il de ce rapport supposé entre le type du Juif Errant et le métier de cordonnier?

Il est vrai que l'association privilégiée de l'éternel marcheur avec les thèmes de la chaussure et de la cordonnerie peut paraître s'imposer «naturellement», ce qui n'empêche pas que celui-ci sera représenté tantôt comme un va-nu-pieds, tantôt comme nanti de bottes ou de chaussures portant le signe de la croix, voire doté de pieds durs comme des sabots de chevaux. Relativement nombreuses sont, on l'a vu, les versions de la légende qui, plus précisément, font de lui un cordonnier ${ }^{65}$ : la plupart dérivent plus ou moins explicitement de la relation allemande ${ }^{66}$. Il est parfois précisé qu'il a frappé le Christ avec une chaussure ${ }^{67}$, qu'il erre en portant sur son dos un sac plein de vieux souliers ${ }^{68}$, qu'il a laissé ses propres chaussures à tel ou tel endroit $^{69}$, que les habitants des lieux qu'il visite lui en donnent de nouvelles ${ }^{70}$, etc.

Indépendamment des traditions galiciennes et pyrénéennes analysées plus haut et des multiples références au Juif Errant que l'on peut relever dans la littérature espagnole du Siècle d'Or, qui font presque toutes allusion à sa profession de cordonnier ${ }^{71}$, et dont il est souvent difficile de savoir si elles doivent ce trait à l'influence paneuropéenne du livret allemand de 1602 ou aux versions et cas ibériques du $\mathrm{XVI}^{\mathrm{e}}$ siècle, on remarque que l'association du personnage

64. Voir Enzyklopädie des Märchens, art. cit., c. 582 sq., J.E. Gillet, op. cit., p. 25 sq., Alexandre Scheiber, Louis Tardy, «L'écho de la première manifestation de David Reubéni dans les brochures de colportage allemandes de l'époque», Revue des Études Juives, 132, 1973, p. 595-601.

65. G.K. Anderson, The legend..., p. 30, 42-48, 72 sq., 81, 98, 102, 121, $163-$ 165, A. Dundes - G. Hasan Rokem (éds.), op. cit., p. 82, 84, Enzyklopädie des Märchens, art. cit., c. 582 sq.

66. Voir supra n. 53.

67. G.K. Anderson, The legend..., p. 121, A. Dundes, G. Hasan Rokem (éds.), op. cit., p. 82.

68. Ibid., p. 132, 140 sq., 179 (assimilation à Saint Nicolas), 162 (versions suédoises analysées par B. af Klintberg). Cf. Georges Dumézil, «Le dieu scandinave Vidarr», Revue de l'Histoire des Religions, 213, 1965, p. 1-13 et Karl Blind, «Wodan, the Wild Huntsman and the Wandering Jew» in A. Dundes, G. Hasan Roken (éds.), op. cit., p. 169-189 (p. 183 sq.).

69. K. Blind, op. cit., G.K. Anderson, The legend..., p. 82 ( $\left.{ }^{\circ} 62\right)$.

70. Ibid., p. 76, 82, J. Amades, op. cit., p. 480 sq. (n 143).

71. Voir supra n. 54. 
à la cordonnerie se retrouve ça et là dans le folklore péninsulaire, notamment en Catalogne, où $\mathrm{J}$. Amades a recueilli, à propos des cordonniers, des traditions qui, implicitement ou explicitement, reconduisent à la légende du marcheur maudit. C'est ainsi que les processions religieuses barcelonaises s'abstiendraient d'emprunter les rues où se trouvent leurs échoppes «per tal d'evitar que algum d'ells sentís revivre dins seu l'esperit del Jueu Errant $\gg^{72}$, et que les formules finales des contes folkloriques catalans font souvent allusion à un cordonnier posté derrière une porte «que tothom que passe li tira del braser $\gg^{73} \ldots$

Il est en outre particulièrement significatif que, dans ces traditions ibériques, la malédiction du Juif Errant soit souvent élargie à l'ensemble des cordonniers et que la légende du marcheur maudit, qui dans la grande majorité de ses versions européennes ne concerne qu'un cas hautement individualisé, y fasse figure de mythe corporatif expliquant les malheurs endurés collectivement par la totalité des représentants de la profession. Il est vrai que cette idée est également présente dans les traditions britanniques et estoniennes, qui imputent à la malédiction encourue par le Juif Errant la responsabilité de la pauvreté qui caractérise tous ses collègues ${ }^{74}$, et que les cordonniers et savetiers qui ont été souvent par le passé soumis à la contrainte de migrations ou de tournées saisonnières ${ }^{75}$ ont dû éprouver, juifs ou non juifs, le sentiment de leur affinité «professionnelle» avec le marcheur maudit ${ }^{76}$. C'est

72. J. Amades, Folklore de Catalunya. Costums i creences, $2^{\mathrm{e}}$ éd., Barcelone: Selecta, 1980, p. 699 sq.

73. Ibid., p. 723.

74. Voir A. Dundes, G. Hasan Rokem (éds.), op. cit., p. 100, K.M. Briggs, op. cit., t.2, p. 510 («The curse of the Shoemaker»), P. Sébillot, «Les cordonniers» (in id., Légendes et curiosités des métiers, Paris, 1895, où chaque chapitre a sa pagination propre), p. 10, G.K. Anderson, The legend..., p. 98 (version estonienne). Voir motifs P 453.1 («Why shoemakers are indolent»: c'est parce qu'un cordonnier avait craché sur Jésus), Q 221-2 («Punishment for opposition to Christ at Crucifixion») et Q 556.1 («Curse for participation in the Crucifixion») du Motif-index of Folk - Literature (Copenhague - Bloomington: Indiana Univ. Pr., Rosenkilde and Bagger, 6 vols., 1955-1958) de Stith Thompson.

75. A. Dundes, G. Hasan Rokem, (éds.), op. cit., p. 122 (sur les guildes médiévales de cordonniers ambulants).

76. Charles Nisard, Histoire des livres populaires ou de la littérature du colportage (rééd.), Paris : Maisonneuve et Larose, 1968, t. I, p. 266 sq. (la «langue du Juif Errant» compte parmi les talismans corporatifs des cordonniers). Les boutiques des cordonniers du $\mathrm{XIX}^{\mathrm{e}}$ siècle étaient souvent décorées de l'image d'Épinal d'Ahasvérus. 
cependant la tradition catalane qui associe avec le plus d'insistance la légende du Juif Errant et le thème du métier maudit: la faute individuelle du cordonnier de Jérusalem n'y apparaît que comme la projection emblématique d'une ignominie collective (renforcée bien sûr par l'idéologie antijuive), comme prétend le démontrer ce conte où l'errance du cordonnier maudit par Jésus lui permet de constater que tous ses confrères ou presque - auxquels il a systématiquement rendu visite au cours de ses pérégrinations de par le monde - ont manifesté à son égard le même manque de générosité dont il avait lui-même fait preuve à l'égard du Christ ${ }^{77}$.

Les cordonniers des contes catalans subissent donc les effets d'une malédiction qui, même lorsqu'elle semble avoir une origine individuelle, prend la forme d'une calamité collective sanctionnant une faute à laquelle tous leurs collègues, d'une manière ou d'une autre, participent. L'évocation de cette faute et de la subséquente malédiction reconduit dans plusieurs cas explicitement à celles du Juif Errant, mais il arrive aussi que la légende relative à ce dernier ne soit pas directement mentionnée: dans ce cas l'allusion sousjacente - plus ou moins transposée - reste néanmoins détectable. La faute en question est en effet presque toujours un manquement à la charité et à l'hospitalité, parfois assorti d'une brutalité qui prend la forme du jet d'un objet lié au métier du coupable (par exemple une forme de cordonnier), d'où la nargue para-proverbiale que, selon Amades, «nos aînés» avaient coutume de lancer aux cordonniers («Arri, sabater maleït, que vas tirar la forma a Déu») ${ }^{78}$. Bien qu'il reconduise globalement à la typologie générale des récits étiologiques expliquant le pourquoi de la malédiction supposée qui pèse sur tel ou tel métier - lesquels se réfèrent souvent, comme dans maintes légendes sur l'origine des caractéristiques de tel ou tel animal ${ }^{79}$, au comportement d'un ou plusieurs représentants de

77. J. Amades, Folklore de Catalunya. Rondallística, p. 480 sq. ( $\left.{ }^{\circ} 143\right)$, J. Camarena, M. Chevalier, op. cit., p.202-204.

78. J. Amades, Petite Cosmogonie Catalane, t. II. Des étoiles aux plantes, trad. fr. Marlène Albert-Llorca, Carcassonne: Garae (Groupe Audois de Recherche et d'Animation Ethnographique)-Hésiode, Pr. Univ. du Mirail, 1994, p. 51 sq. $\left(n^{\circ} 391\right)$.

79. Sur ce genre de récit voir M. Albert-Llorca, L'ordre des choses. Les récits d'origine des animaux et des plantes en Europe, Paris: Comité des Travaux Historiques et Scientifiques, 1991, et l'ouvrage classique d'Oskar Dähnhardt, Natursagen, Leipzig-Berlin, 1907-1912. 
la profession lors de la Passion du Christ $^{80}$-, le schéma narratif qui articule ces contes est donc traversé de manière récurrente et spécifique par le mythe de l'éternel marcheur.

Même dans les versions qui semblent s'éloigner de ce mythe, par exemple celles qui remplacent l'errance punitive par une quête rédemptrice, son influence peut être décelée: dans les histoires catalanes de cordonniers qui font pénitence - le plus souvent en parcourant le monde - pour échapper à une malédiction initiale (parfois inexpliquée) $^{81}$ et qui finissent par devenir papes, ce qui est mis encore une fois au premier plan c'est la charité envers le visiteur qui demande l'aumône ou l'hospitalité, et le manquement à cette vertu est, au moins dans une des versions recueillies, matérialisé par une tache sanglante qui, comme le «signe de Caïn» ou mieux la marque portée - au front ou à la main - par le Juif Errant, révèle à tous la malédiction dont il est porteur et permet de le reconnaitre ${ }^{82}$. Ce motif de la «marque» du Juif Errant qui connaîtra, tardivement, une importante destinée littéraire et iconographique ${ }^{83}$ a eu précisément en Espagne un développement précoce et privilégiér ${ }^{84}$.

Certains contes catalans redécouvrent cependant, au-delà de l'exemplum sur la charité, le thème sous-jacent du sacrilège, dont nous avons vu qu'il est au centre du folklore des cordonniers et dont le mythe du Juif Errant n'explicite qu'un aspect secondaire (celui du sacrilège involontaire et inconscient: le cordonnier de Jérusalem ne sait pas qu'il a affaire à Dieu incarné et sa punition paraît de ce

80. Cf. supra n. 74. Voir J. Amades, Petite Cosmogonie Catalane, t. II, p. 49-57 (n $\left.{ }^{\circ} 396-399\right)$.

81. J. Amades, Folklore de Catalunya. Costums i creences, p. 715 sq. (maudit dès sa naissance, affectée d'une prédiction fatale).

82. Ibid., p. 716 (tache de vin indélébile).

83. On le retrouve notamment dans les premières versions littéraires du mythe (Le Moine de M.G. Lewis et Le Manuscrit trouvé à Saragosse de J. Potocki: voir Edgar Knecht, Le mythe du Juif Errant, Grenoble: Presses Universitaires de Grenaoble, 1977, p. 130-135 et Marie-France Rouart, Le mythe du Juif Errant, Paris: J. Corti, 1988, p. 49-55). La marque est souvent cruciforme et peut être portée sur le front (c'est le cas dans les versions littéraires citées ci-dessus) ou sur le bras et/ou la main (marque du pseudo-Juif Errant ibérique: il s'agit alors de l'empreinte d'une horma), voire sur les semelles des chaussures, qui marquent à leur tour le sol foulé par l'éternel pèlerin. Le motif est complexe et mérite une étude spécifique.

84. Voir M. Bataillon, op. cit., p. 88, 107, 111 sq., 115, 121-124, 131 sq., et F. Delpech, «Devine qui vient dîner ce soir...», p. 176-178. Cf. id., «La «marque des sorcières» : logique(s) de la stigmatisation diabolique», in Le Sabbat des Sorciers $X V^{e}-X V I I I^{e}$ siècles, N. Jacques-Chaquin, M. Préaud (éds.), Grenoble: J. Millon, 1993, p. 237-368 (p. 355 sq.). 
fait quelque peu exorbitante). Ce thème essentiel est par exemple au cœur du conte du $\left\langle\right.$ sabater damnat ${ }^{85}$, où nous retrouvons l'image du cordonnier joyeux drille et pilier de tripot (qui a d'ailleurs installé son échoppe dans une auberge !): sur le passage de la «campaneta del combregar» il se livre, avec force coups de marteau sur une semelle, grimaces et gestes moqueurs, à une dérision sacrilège du Sacrement; en punition de cette irrévérence il est condamné à rester ainsi, «mentre el món será món», planté à la porte de l'auberge «picant sola a la desesperada, sense poder-se alçar ni deixar de fer ganyotes i gestos estranys ». Avec le temps l'auberge a disparu; l'endroit est désormais perdu dans un désert pyrénéen aride et escarpé, mais le cordonnier est toujours là, subissant «per tota l'eternitat» les aléas climatiques et poursuivant sans arrêt son manège blasphématoire. Il n'est plus question ici de juif errant: le «sabater damnat» n'est ni juif ni puni par une éternelle errance; il est au contraire à jamais fixé et son histoire se déroule entièrement dans le cadre péninsulaire. On reconnaît cependant le thème du changement écologique catastrophique ici un retour du paysage à l'état sauvage - et la si caractéristique extension de la malédiction (ici associée au thème déjà signalé de la vocation liminaire des cordonniers): "Diven que la maledicció d'aquest sabater arriba a tots els del mateix ofici i que per aixó són molts els qui treballen al peu de les portes i de les escaletes $» . .$.

$$
* * *
$$

On voit donc fleurir dans le folklore de la péninsule Ibérique toute une série de récits de cordonniers transgresseurs qui parfois s'identifient à la légende du Juif Errant, parfois seulement la recoupent par quelque motif, et occasionnellement s'en écartent. Ce qui reste constant c'est le thème du cordonnier maudit qui, s'il déteint sur le cycle du marcheur éternel, semble avoir une existence autonome et le déborder de toutes parts. Peut-être même lui est-il antérieur et a-t-il contribué à sa formation, hypothèse qu'il y aura lieu d'examiner ultérieurement dans un travail spécialement consacré à cette question ${ }^{86}$.

85. J. Amades, Folklore de Catalunya. Rondallística, p. 974 sq. ( $\left.{ }^{\circ} 390\right)$.

86. Le problème, dont l'étude a été ébauchée dans F. Delpech, «Savetiers prodigieux et cordonniers sacrilèges...», sera remis sur le métier dans un travail consacré aux versions orientales du motif du «cordonnier sacrilège». 
On retiendra seulement ici que l'ampleur et la persistance de cette représentation dans les traditions orales de la péninsule Ibérique, le fait qu'elle y précède de plus d'un demi-siècle la première manifestation européenne (le livret allemand de 1602) de l'association Juif Errant - cordonnier sacrilège et qu'elle y apparaisse, durablement, comme relativement autonome par rapport au cycle international consécutif à cette manifestation, permettent d'envisager sérieusement l'hypothèse de l'origine ibérique du complexe thématique en question.

En outre les remarques formulées dans la première moitié de cet exposé autour du cas Reubeni conseillent plus précisément de postuler une origine judéo-ibérique de ce complexe, étant entendu par là qu'ont dû concourir à sa formation aussi bien des idées et des images issues des milieux juifs que les contre-idées et les contreimages élaborées et diffusées, en milieu vieux-chrétien, pour les contrecarrer (tout en les récupérant, moyennant détournement de leur sens originel). Le dossier du «Juif au soulier» semble donc particulièrement symptomatique. Sans vouloir tout faire remonter au seul cas de l'affaire Reubeni, qui n'est certainement qu'un élément (à la fois donneur et récepteur d'images) dans un ensemble plus complexe, largement interactif, de croyances, de légendes et d'associations mentales, on peut se demander si sa notoriété n'a pas précipité la coagulation de stéréotypes latents qui se fixeront finalement sur l'image-standard du Juif Errant-cordonnier.

On ne peut manquer, dans cette perspective, d'être frappé par une intéressante coïncidence: si c'est une brochure «populaire» allemande qui, en 1602, a imposé pour toute l'Europe cette image désormais topique, ce sont aussi, précisément, des brochures de colportage allemandes (Strasbourg, 1523; Nuremberg, 1523; Cologne, 1574) qui, sans le nommer, mais dès l'année même de son entrée en lice dans le champ de l'Histoire, ont le plus largement célébré le fracassant «coming out» de Reubeni et de ses imaginaires légions de juifs perdus, récemment sortis de leur millénaire retraite pour reconquérir la Terre Promise... ${ }^{87}$.

Au terme de cette étude, il n'apparaît, somme toute, pas inutile de supposer qu'il y a eu une corrélation entre l'image d'Énoch comme cordonnier, celle du Juif Errant comme exerçant la même 
profession et la définition de David Reubeni en tant que «juif au soulier». Ce dernier semble avoir assuré, à son corps défendant, la transition entre la version énochienne, positive, du cordonnier mystique et la version, toute négative ${ }^{88}$, de l'éternel marcheur maudit: au fur et à mesure que la pérégrination messianique du prophète se transformait en marche de l'imposteur vers le bûcher, le symbolique soulier changeait de signe. Le basculement de la carrière de celui dont la chaussure était l'emblème a précipité la dissociation définitive des deux aspects d'une image primitive complexe et ambivalente dont il avait été, peut-être dès le début, confusément tributaire: de ce stéréotype hérité, où se mêlent et entrecroisent les types contradictoires du saint cordonnier et du cordonnier sacrilège, il y a donc maintenant lieu d'étudier les racines orientales. Mais c'est un tout autre voyage.

15, rue du Faubourg Saint-Antoine 75011 Paris

francois.m.delpech@wanadoo.fr

88. Voir supra n. 86. 